\title{
Ethological analyses of crayfish behavior: a new invertebrate system for measuring the rewarding properties of psychostimulants
}

\author{
Jules B. Panksepp ${ }^{\mathrm{a}, *}$, Robert Huber ${ }^{\mathrm{b}}$ \\ a 7225 Medical Sciences Center, University of Wisconsin-Madison, 1300 University Ave., Madison, WI 53706-1532, USA \\ b J.P. Scott Center for Neuroscience, Mind \& Behavior and Department of Biological Sciences, Bowling Green State University, USA
}

Received 8 August 2003; received in revised form 23 November 2003; accepted 25 November 2003

Available online 1 February 2004

\begin{abstract}
Recent investigations in invertebrate neurobiology have opened up a new line of research into the basic behavioral, neurochemical and genomic alterations that accompany psychostimulant drug exposure. However, the extent to which such findings relate to changes in motivational and learning processes, such as those that typify drug addictions, remains unclear. The present study addressed this issue in the crayfish, Orconectes rusticus. The first set of experiments demonstrated that intramuscular injections of cocaine and amphetamine have robust and distinguishable effects on crayfish behavior. In the second part of the study, the reinforcing properties of psychostimulants were tested in a series of conditioned place preference experiments. Amphetamine and, to a lesser extent, cocaine were both found to serve as rewards when their intra-circulatory infusion was coupled to a distinct visual environment. The monoaminergic regulation of behavior has been extensively studied in decapod crustaceans and the present experiments demonstrated that (mammalian) drugs of abuse, capable of interfering with monoamine chemistry, are similarly rewarding to crayfish. Behavioral studies in crayfish can provide a complementary approach to using other invertebrate species in addiction research.
\end{abstract}

(C) 2004 Elsevier B.V. All rights reserved.

Keywords: Conditioned place preference; Drug reward; Addiction; Amphetamine; Cocaine; Decapoda; Crustacea; Arthropoda

\section{Introduction}

Invertebrate model systems have recently figured with increasing prominence in drug addiction research. For example, initial work in fruit flies $[39,58]$ and planarians [46] characterized a series of dose-dependent, stereotypical motor behaviors that accompany cocaine administration. With patent similarities to the behavioral effects of cocaine in mammals (reviewed in ref. [62]), these findings were essential to the establishment of invertebrate approaches in addiction research $[7,33,58,65]$. Two further insights have illustrated the conceptual validity of psychostimulant sensitivity in invertebrate species: first, consistent with antagonist and lesion studies in mammals (e.g., refs. $[31,60]$ ), dopamine (DA) modulates the behavioral efficacy of cocaine administration $[4,35,46,58]$. Moreover, fruit flies exhibit a form of behavioral sensitization $[38,39]$ that resembles the protracted neuro-behavioral effects of psychostimulants in the mammalian brain (reviewed in refs. $[9,29,48]$ ).

\footnotetext{
* Corresponding author.

E-mail address: jbpanksepp@wise.edu (J.B. Panksepp).
}

Novel mechanisms potentially involved in drug addictions have also emerged from studies of Drosophila. For instance, the trace amine tyramine (TA) appears to play an integral role in the development of behavioral sensitization to cocaine [38] such that circadian gene regulation, TA biosynthesis and behavioral sensitization are tightly coupled in fruit flies [2]. Interestingly, subsequent work in mammals demonstrated the importance of circadian rhythmicity for psychostimulant sensitization [1,44] and, furthermore, identified a population of high-affinity TA receptors in the ventral tegmental area [11], a focal region of DA-rich cell bodies thought to be a primary component of reward circuitry in the mammalian brain. Although trace amines like TA have historically received less experimental attention than other monoamines, there exists a large literature documenting their relationship to disturbances in affect and cognition (see ref. [50]), and thus psychostimulant studies in flies may also provide a new source of hypotheses regarding drug addictions.

However, despite the many parallels between fruit flies and mammals, whether addictive drugs can be rewarding to an invertebrate has yet to be examined thoroughly. Electrical stimulation [5], biogenic amines [40] or food items [45] 
have served as rewards in past studies of invertebrates and in some cases there has since been considerable advance into understanding the underlying proximate mechanisms of such processes (e.g., ref. [12]). A recent study, where planarians were conditioned to prefer environments associated with methamphetamine treatments, was a notable exception to the general lack of explicit studies of drug reward in invertebrate taxa [33]. Yet, aside from that study and for preliminary evidence of ethanol reward in Drosophila [23], drug reward in an invertebrate species has remained largely unexplored.

Decapod crustaceans, such as crayfish and lobsters, have been used extensively in neuroethology (reviewed in refs. $[19,32])$, making their use potentially ideal for studies of invertebrate drug reward. Due to their anatomical and physiological characteristics [8,24,37], as well as their accessibility to pharmaco-behavioral manipulations [28,47], monoamine neuromodulatory systems have received particular emphasis in previous research with decapod crustaceans. Furthermore, evidence for conserved, monoamine re-uptake mechanisms in invertebrates $[15,18,49]$ suggests the existence of the requisite sites of action (e.g., see ref. [28]) for testing drug-sensitive reward in this group.

This paper reports a set of characteristic, stable and robust changes in crayfish behavior that resulted from treatment with psychostimulant drugs of abuse. The first set of experiments examined the consequences of intramuscular cocaine and amphetamine injections on crayfish behavior. In the second set of experiments, a conditioned place preference procedure was employed to test the rewarding properties of psychostimulants delivered into the crayfish circulatory system. Together with other recent studies, the present experiments demonstrated the advantages of using invertebrate species to help characterize the basic biological processes underlying psychostimulant exposure.

\section{Materials and methods}

\subsection{Animals}

Crayfish, Orconectes rusticus, were collected from the Portage River near Bowling Green State University in Bowling Green, OH, USA. Once in the laboratory, animals were isolated in plastic containers $(160 \mathrm{~mm}$ diameter, $95 \mathrm{~mm}$ depth) and maintained in flow-through holding trays that received freshly filtered/aerated water kept at $20 \pm 1{ }^{\circ} \mathrm{C}$. Crayfish were fed 1-2 times per week with tuna fish, earthworms or rabbit chow, and housed under a 16:8 h light/dark cycle. Only intermolt males that possessed a full complement of intact appendages and were socially isolated for $>3$ days were used.

\subsection{Behavioral experiments}

Initial experiments were focused on characterizing the general behavioral effects of psychostimulant drug admin- istration in crayfish. Crayfish (15.2-27.9 g) were randomly distributed into seven treatment groups ( $n=5$ per group). D-Amphetamine sulfate (FW: 368.5; Sigma, St. Louis: A 5880) or cocaine $\mathrm{HCl}$ (FW: 339.8; Sigma, St. Louis: C 5776) was administered systemically at $2.5,5.0$ and $10.0 \mu \mathrm{g} / \mathrm{g}$ body weight (dosages refer to free base concentrations), with a vehicle-injected (125 mM saline) group serving as controls. Total injection volumes were adjusted to $1 / 50$ of the estimated hemolymph volume for each crayfish (which was determined in previous experiments) and were delivered ventrally into the second abdominal segment, lateral to the nerve cord. The syringe was held in place for approximately $10 \mathrm{~s}$ to prevent leakage from the injection site.

Immediately following an injection, each animal was placed into a Plexiglas aquarium $(450 \mathrm{~mm} \times 320 \mathrm{~mm} \times$ $145 \mathrm{~mm}$ ) lined with gravel substrate and videotaped for 30-60 min with a digital camcorder (XL1, Canon, Japan). Videotapes were blinded and analyzed in formats ranging from real-time to frame-by-frame playback. Several conspicuous behavior patterns and postures were noted during the experiments and were subsequently compared to an ethogram designed for crayfish placed into a novel environment (see Table 1 for behavioral descriptions). Behavioral categories were assigned to individual crayfish at $5 \mathrm{~s}$ intervals for the first $25 \mathrm{~min}$ post-injection. Categories from the ethogram were considered to be mutually exclusive in that a single category was given for each $5 \mathrm{~s}$ interval. This was achieved by assigning the behavioral category that occurred for the majority of each $5 \mathrm{~s}$ interval. To describe psychostimulant-induced behavioral effects in the most comprehensive fashion, several statistical techniques (e.g., ANOVA and principal components analysis) were used for the behavioral analysis.

\subsection{Conditioned place preference experiments}

A preliminary set of experiments explored the spatial characteristics of crayfish locomotion within the test aquarium. Individual crayfish $(n=10)$ were placed in the aquarium on 2 successive days for $60 \mathrm{~min}$, and their movement and spatial distribution were measured (see below for descriptions of the aquarium and video tracking system).

In the next set of experiments, a conditioned place preference (CPP) procedure was used to test the rewarding properties of amphetamine and cocaine on crayfish behavior. One day before the conditioning trials began, crayfish were anesthetized in crushed ice for $\sim 15 \mathrm{~min}$. A 26.5 gauge needle was used to drill a hole in the caudal $1 / 3$ of the dorsal carapace, lateral of the midline to avoid damaging the underlying heart. $15 \mathrm{~mm}$ of deactivated, fine-bore, fused silica (Agilent, i.d. $=250 \mu \mathrm{m}$ ) was implanted into the pericardial sinus (allowing $3 \mathrm{~mm}$ to enter the sinus), and secured with small pieces of paper towel and cyanoacrylate. Animals were placed back in their holding containers to recover overnight. This method of drug administration is particularly useful in crustaceans, as the pericardial organs are primary sites of 
Table 1

Ethogram describing the behavioral tendencies of crayfish when placed in a novel aquarium

\begin{tabular}{ll}
\hline Behavior & Behavioral description \\
\hline Inactive & Does not move in space. Most appendages are not \\
active, although the mouthparts may periodically \\
move in a rhythmical fashion \\
Forward walking \\
Mearing \\
Moves forward anywhere in the aquarium \\
Stands on hindmost pair of walking legs, typically \\
using the posterior region of the abdomen for \\
support as the remaining three pairs of walking \\
legs move in a pattern similar to that used for \\
forward locomotion. Occurs a majority of the time \\
in the corners of the aquarium \\
Approaches a corner of the aquarium, places \\
second antennae on the wall(s) and uses them for \\
tactile investigation of the aquarium perimeter \\
Brings 1 or both front walking legs to mouth area \\
in a sequence that resembles feeding. From \\
time-to-time a piece of gravel is placed in mouth \\
and manipulated \\
Four distinct forms of grooming behavior were \\
pooled together under the category of 'grooming' \\
for the principle components analysis \\
Ventral side grooming-Contracts thorax and \\
abdomen, and uses walking legs to clean \\
underside \\
Dorsal side grooming-Uses posterior two pairs \\
of walking legs to clean the dorsal region of its \\
abdomen, or its anterior two pairs of walking \\
legs to clean its eyestalks or claws \\
Antennae grooming - Uses third maxillepeds to \\
grasp second antennae near their base. The base \\
of an antenna is then moved upward and back \\
toward the eyestalk, allowing the entire length of \\
the antenna to be pulled through the maxillepeds. \\
This occurs once or in a repeated sequence \\
Antennule grooming-Follows the same \\
sequential order as antennae grooming except \\
that the first antennae (i.e., the medial/lateral \\
antennules) are the appendages that are groomed
\end{tabular}

Behavioral categories were based on observations of crayfish behavior in the field, laboratory and throughout testing. Behaviors occurring $<1 \%$ of the overall time were not included in the final ethogram. These included 'tail flip' and 'backwards locomotion.' Locomotion was initially divided into 'fast' $(>1 \mathrm{~cm} / \mathrm{s})$ and 'slow' $(<1 \mathrm{~cm} / \mathrm{s})$. However, fast locomotion occurred infrequently and thus this distinction was not used in the final analysis.

releasable monoamines $[13,20,36]$ and amine manipulations in the blood ultimately reach the nerve cord [26].

Conditioning trials were carried out in a Plexiglas aquarium $(525 \mathrm{~mm} \times 525 \mathrm{~mm} \times 150 \mathrm{~mm})$ with opaque walls and a clear, sand blasted floor (for traction). A continuous supply of water was provided by in/out tubes located at the center of each wall that were connected to a reservoir (681 capacity), where water was aerated and mixed before being pumped into the aquarium. A lighting system, comprised of five uniformly oriented strip lamps (equipped with $15 \mathrm{~W}$ fluorescent bulbs) and a layer of paper (for light diffusion), illuminated the aquarium from below. The aquarium was divided into four compartments of equal area such that distinct

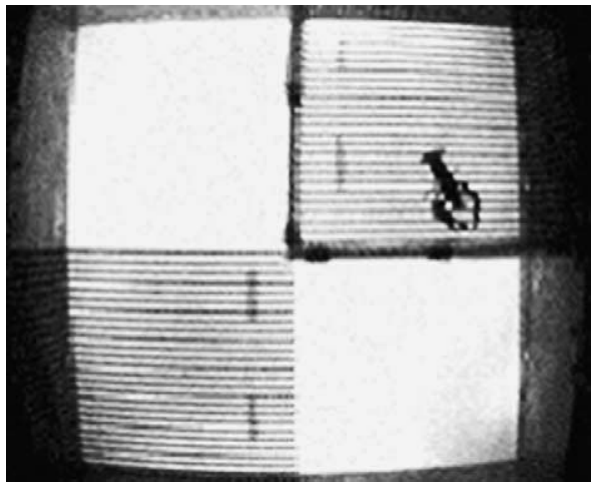

Fig. 1. Overhead view of the arena used for the CPP experiments. An aquarium was constructed with Plexiglas and the floor was roughened with a sand blaster to provide additional traction for crayfish walking. A lighting system was situated below the aquarium in order to enhance the resolution of video tracking. An adjustable camera was mounted above the arena and video tracking analyses were carried out with custom-written, Java-based computer software. As illustrated in the picture above, crayfish were isolated in a distinct visual environment when receiving respective drug or vehicle infusions. Crayfish were allowed to move freely about the entire arena during test sessions that occurred following 5 successive days of psychostimulant conditioning.

visual environments were always present in adjacent compartments (Fig. 1). The visual environments were created by lining the inner walls and outer floor of each aquarium compartment with plastic transparencies that were either clear (which made the environment uniformly white due to the color of the Plexiglas and paper; i.e., the 'uniform' environment), or rather had a continuous array of $10 \mathrm{~mm}$ wide, alternating black and white stripes that were orientated vertically on the walls (i.e., the 'striped' environment).

Video tracking was carried out with freeware, Java-based software included with the JavaGrinders package (available at http://caspar.bgsu.edu/ software/java/). In short, an adjustable video camera was mounted above the aquarium and the video signal was fed into a video digitizer on a Power Macintosh (8100/100AV) computer. The video tracking program was set to extract the spatial coordinates of a crayfish from a single video frame at a temporal resolution of $1 / 3 \mathrm{~Hz}$.

The conditioning experiments commenced on the day after surgery. $\sim 0.5 \mathrm{~m}$ of deactivated, fine-bore, fused silica needle material (Agilent, i.d. $=100 \mu \mathrm{m}$ ) was connected to a cannulated crayfish with Tygon microbore tubing (Fisher Scientific, i.d. $=250 \mu \mathrm{m}$ ) and ran to a microdialysis swivel (Instech, 375/25P) mounted above the aquarium. Drugs were administered into the pericardial sinus with a microdialysis pump (CMA/102). Prior to connecting an animal, the cannula was primed to fill its void volume so as to insure that drug infusions began immediately when the pump was turned on.

Crayfish (11.6-33.7 g) were randomly assigned into five groups ( $n=12$ per group): control, uniform/amphetamine, striped/amphetamine, uniform/cocaine or striped/cocaine. Thus, all possible pairwise combinations of environment and drug were tested. For example, in the uniform/amphetamine 
group a crayfish would receive amphetamine infusions in the uniform environment and isometric vehicle $(125 \mathrm{mM}$ saline) infusions in the striped environment, and so on for all of the remaining environment/drug combinations. The control group consisted of crayfish that received vehicle infusions in both the uniform and striped environments.

A conditioning session entailed connecting an animal to the infusion cannula and placing it in an isolated quadrant (see Fig. 1). This was achieved with a removable Plexiglas enclosure that had walls corresponding to each respective visual environment. Amphetamine $(5.0 \mu \mathrm{g} / \mathrm{g}$ body weight $)$ or cocaine $(2.5 \mu \mathrm{g} / \mathrm{g}$ body weight $)$ infusions began immediately after a crayfish was placed in the aquarium and were delivered continuously for the first $5 \mathrm{~min}$ of the session. Crayfish were allowed to move freely about the respective compartment for an additional $25 \mathrm{~min}$. On 5 successive days each animal received two conditioning sessions per day (separated by $8-12 \mathrm{~h}$ ), one in each environment in random order (i.e., psychostimulant-treated crayfish received 1 drug and 1 vehicle infusion/day while crayfish in the control group received 2 vehicle infusions/day). For the test trial, each crayfish was placed into the center of the aquarium on day 6 and was allowed access to the entire aquarium in a drug-free state for $60 \mathrm{~min}$. To insure that infusions had been successfully delivered into the pericardial sinus throughout the conditioning sessions, a $20-60 \mu \mathrm{g}$-cocaine infusion was given to every animal after being tested for CPP (cocaine administration produced a robust and reproducible behavioral response that indicated successful treatment; see Section 3).

In a third set of experiments, the same conditioning procedure was used except that only a single day of conditioning sessions was given before the test trial. Drug-conditioned crayfish received only a single experience with drug and vehicle respectively before the test trial, while individuals in the control group were given two experiences with vehicle. Furthermore, only a control group $(n=8)$ and a striped/amphetamine group $(n=10)$ were used, as the striped/amphetamine combination was found to be the most sensitive to drug effects in the 5-day CPP experiments. In all three sets of experiments, parametric statistics were used to evaluate locomotion/spatial patterns and the existence of psychostimulant-induced CPP.

\section{Results}

\subsection{Systemic injections of cocaine and amphetamine produce characteristic changes in crayfish behavior}

Irrespective of dose, intramuscular cocaine injections were always associated with a static posture that was characterized by an overall flexion of the abdomen and walking legs, and claws that pointed downward and out in front of the thorax (Fig. 2A). Due to the rigidity that accompanied this method of cocaine administration, crayfish often lost the ability to right themselves and were therefore excluded from
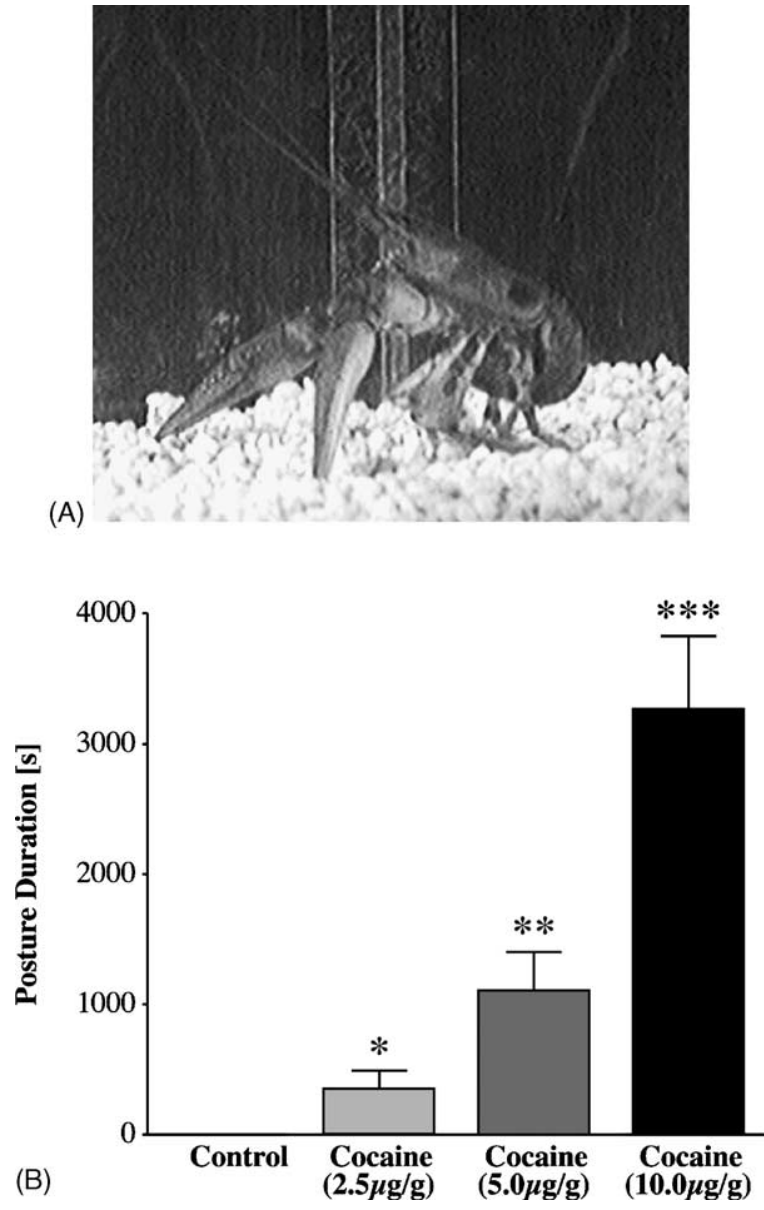

Fig. 2. Effects of cocaine injections on crayfish behavior. (A) At every dosage tested characteristic, static postures always accompanied cocaine injections. (B) The duration that the posture was displayed was dose dependent $\left(F_{[3,16]}=156.11, P<0.001\right)$, with Tukey's HSD post hoc tests differentiating all groups from each other $(*, * *, * * *, P<0.05)$ Log-transformations were applied to fit the data to a normal distribution.

the ethological analysis. The duration of the cocaine-induced posture was dose dependent (Fig. $2 \mathrm{~B} ; F_{[3,16]}=156.11, P<$ 0.001). Similar posturing occurred after intra-pericardial cocaine infusions (during the CPP experiments) although it took place with a slower onset and more rapid disappearance. Following this route of cocaine treatment, crayfish behavioral patterns were marked by rapid backwards walking, claw waving and often concluded with a series of tail flips before assuming the static posture described above. All behavior patterns elicited by psychostimulants in crayfish can be viewed as Quicktime movies on the Internet at http://caspar.bgsu.edu/ crayfish/psychostimulant/reward/.

Compared to cocaine, amphetamine treatment resulted in a markedly different set of behavioral effects. Static postures were never observed following amphetamine injections; rather, amphetamine-injected crayfish invariably situated themselves in an aquarium corner and began to investigate the perimeter walls with their antennae (see Table 1 and website). Small muscle tremors in the walking 


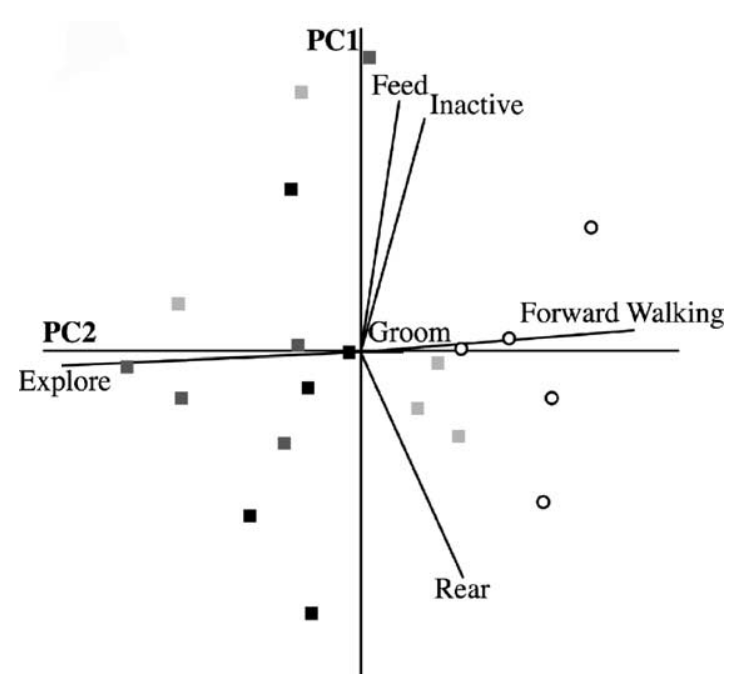

Fig. 3. Effects of amphetamine injections on crayfish behavior. PCA is a valuable data analysis tool when several dependent variables are highly correlated (i.e., to some extent the variables measure the same phenomenon). In essence, PCA constructs linear combinations of dependent variables (PC axes) that subsequently serve as a new coordinate system for interpreting the data set. For PCA to be successful, the data should be parsimoniously explained with a smaller number of derived axes that continue to represent a large amount of the behavioral variation. Depicted above is a multi-dimensional space that is plotted with respect to the $2 \mathrm{PC}$ axes that explained the most behavioral variation $(68.4 \%$ of the variation was accounted for by PC1 and PC2). The original dependent variables (i.e., ethogram categories) are represented by eigen vectors (otherwise known as factor loadings) whose direction depicts the covariance structure in the data set and whose magnitude represents the respective variation explained. Ethogram categories were assigned to individual crayfish at $5 \mathrm{~s}$ intervals for the first 25 min post-treatment. Categories from the ethogram of crayfish behavior were highly correlated (ranging from -0.76 to 0.54 ) and thus the data were well suited for PCA. $\mathrm{e}^{\log }$ transformations were applied to meet the assumptions of normality and equality of variances. Three major sources of behavioral heterogeneity were identified, with a significant degree of separation between amphetamine-treated crayfish (light grey squares, $2.5 \mu \mathrm{g} / \mathrm{g}$; grey squares, $5.0 \mu \mathrm{g} / \mathrm{g}$; and black squares, $10.0 \mu \mathrm{g} / \mathrm{g}$ ) and controls (open circles) on PC2 $\left(F_{[3,16]}=11.08, P<0.001\right)$. PC2 had large factor loadings for the explore and forward walking categories. Although the antennal exploration response was relatively common in the control group (mean \pm S.E.; $12.9 \pm 6.49 \%$ of the total observation time), crayfish injected with amphetamine would immediately seek out an aquarium corner and begin behaving in such a way for prolonged periods of time $(2.5 \mu \mathrm{g} / \mathrm{g}, 33.1 \pm 9.78 \% ; 5.0 \mu \mathrm{g} / \mathrm{g}, 51.9 \pm 9.74 \% ; 10.0 \mu \mathrm{g} / \mathrm{g}$, $41.1 \pm 10.29 \%)$.

legs were apparent at higher doses and from time to time a rapid upwards movement of the whole body was observed.

A principal components analysis (PCA; see the legend of Fig. 3 for analysis details) identified three major sources of heterogeneity that together explained $86.2 \%$ of the total behavioral variation observed during the first $25 \mathrm{~min}$ post-drug treatment (Fig. 3). The first principal components axis (PC1) was strongly weighted by the ethogram categories inactive, feed and rear such that periods of inactivity and stereotypical feeding movements co-occurred (i.e., they were highly correlated) in lieu of rearing in the aquarium corners. Principal component values for PC1 were distributed evenly across all experimental groups $\left(F_{[3,16]}=0.48, P=0.703\right)$.
PC2 differentiated amphetamine-treated crayfish from controls $\left(F_{[3,16]}=11.08, P<0.001\right)$. Explore and forward walking had large factor loadings on PC2, and correlated negatively in such a way that crayfish either spent a large amount of the observation period walking about the aquarium or instead explored the perimeter with their antennae. Amphetamine-injected crayfish spent significantly more time exploring the corners of the aquarium (mean $\pm \mathrm{S}$.E. of the total observation time; control, $12.9 \pm 6.49 \%$; $2.5 \mu \mathrm{g} / \mathrm{g}, 33.1 \pm 9.78 \% ; 5.0 \mu \mathrm{g} / \mathrm{g}, 51.9 \pm 9.74 \% ; 10.0 \mu \mathrm{g} / \mathrm{g}$, $\left.41.1 \pm 10.29 \% ; F_{[3,16]}=6.62, P<0.01\right)$.

On PC3, grooming was the sole ethogram category with a high factor loading. Following approach to an aquarium corner, several amphetamine-treated crayfish carried out repeated bouts of grooming, particularly of the ventral side (see Table 1 and website). The PCA revealed no differences in the amount of time spent grooming $\left(F_{[3,16]}=0.16, P=\right.$ 0.922). However, due to a combination of small sample sizes and the relatively short amount of time it took to complete a single bout of grooming this particular measure may have been insensitive to drug effects. Thus, a separate analysis focusing on the frequency of grooming behaviors was carried out and, although statistically insignificant (Kruskal-Wallis ANOVA; $\left.\chi_{[3]}^{2}=2.21, P=0.529\right)$, there nevertheless remained a noteworthy pattern with respect to the number and variability of ventral side grooming bouts (mean \pm S.E.; control, $1 \pm 1 ; 2.5 \mu \mathrm{g} / \mathrm{g}, 2 \pm 1 ; 5.0 \mu \mathrm{g} / \mathrm{g}, 5 \pm 2 ; 10.0 \mu \mathrm{g} / \mathrm{g}$, $9 \pm 4)$.

\subsection{Untreated crayfish exhibit non-random spatial patterns in the conditioning arena}

An initial group of animals was tested to characterize the natural spatial patterns of crayfish in the aquarium that was used for the drug conditioning experiments. The first day of testing revealed a modest, but statistically significant, natural preference for the uniform environment $(55.8 \pm 2.47 \%$ of total time spent in the uniform environment; two-tailed $t$-test $\left.[\mu=50.0 \%] ; t_{[9]}=2.33, P<0.05\right)$. Although the same general pattern was present on day 2 , the response became approximately two-fold more variable $(54.1 \pm 4.30 \%$ of total time spent in the uniform environment; two-tailed $t$-test $\left.[\mu=50.0 \%] ; t_{[9]}=1.05, P=0.316\right)$. Overall, a paired, two-tailed $t$-test demonstrated that the group preference for the uniform environment was stable across both days $\left(t_{[9]}=0.41, P=0.689\right)$.

Analysis of the spatial behavior of individual crayfish allowed for the appropriate controls to be employed in the CPP experiments. Had individual crayfish served as their own control condition in the present drug conditioning experiments-such as determining the preference of each individual via an initial screening trial (e.g., ref. [33]) - the inter-trial consistency of such a putative environmental preference would have been equivalent to a coin flip (i.e., 5 of the 10 crayfish switched the environment they spent a majority of time in across the 2 days 
Table 2

The spatial distributions of crayfish were monitored on 2 successive days in the test aquarium

\begin{tabular}{lllll}
\hline Crayfish i.d. & Environment & Day $1(\%)$ & Day 2 $(\%)$ & Switch? \\
\hline 18 & Striped & 43 & 46 & No \\
16 & Striped & 43 & 44 & No \\
T45 & Striped & 47 & 52 & Yes \\
T7 & Striped & 51 & 49 & Yes \\
183 & Striped & 29 & 21 & No \\
T51 & Striped & 53 & 35 & Yes \\
135 & Striped & 49 & 69 & Yes \\
259 & Striped & 32 & 36 & No \\
F13 & Striped & 46 & 48 & No \\
13 & Striped & 49 & 59 & Yes \\
\hline
\end{tabular}

Illustrated above is the percentage of time that each crayfish spent in the striped environment of the aquarium on test days 1 and 2. On day 2, 5 of the 10 crayfish switched the environment that they had spent a majority time in on day 1.

of observation; Table 2). Together with the prior analysis, this result suggested the existence of a stochastic preference for the uniform environment that was expressed at the level of the entire experimental population-a preference that was replicated two additional times in the subsequent CPP experiments (Fig. 4). This finding thus guided the decision to use an independent control group, instead of a within-subjects design, in the drug-conditioning experiments.

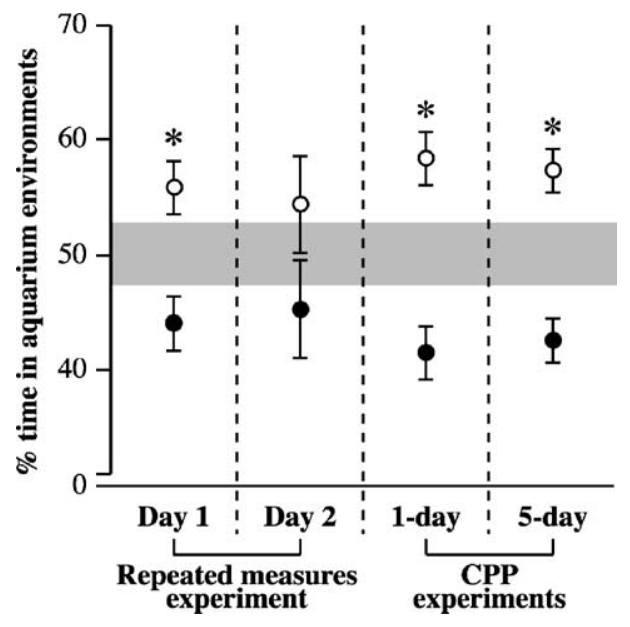

Fig. 4. In three independent experiments, O. rusticus exhibited a population-level preference for the uniform compartments of the conditioning aquarium. Based on a null hypothesis that crayfish would spend equal amounts of time in each of two environments (i.e., $\mu=50.0 \%$ ), two-tailed $t$-test statistics revealed significant deviations from ' $50 / 50$ ' spatial distributions in 3 out of 4 analyses of the natural spatial patterns of crayfish in the test aquarium $(*, P<0.05)$. Reported are the times (mean \pm S.E.) spent in the uniform (open circles) and striped (closed circles) environments by groups of untreated crayfish from three separate experiments. The shaded region represents the 95\% confidence interval for the expected time spent in each environment under the null hypothesis (viz., if crayfish spatial behavior was random, the average amount of time spent in each environment would fall within this region for 95 out of every 100 similarly sampled groups).
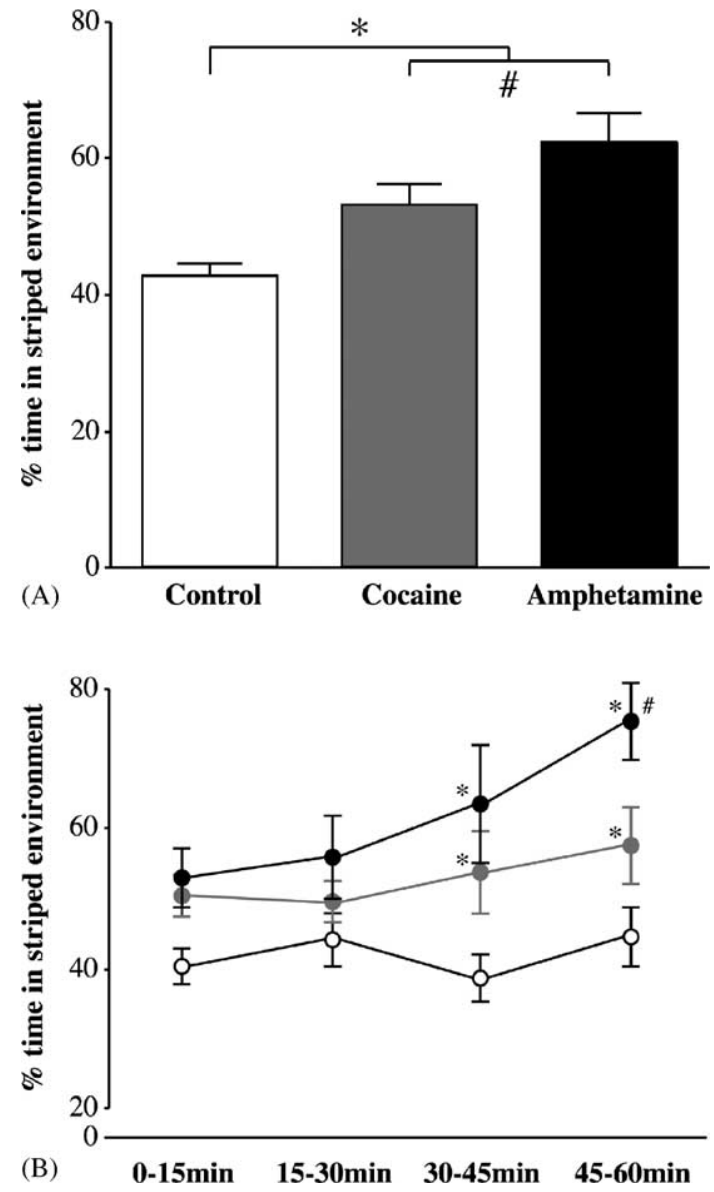

Fig. 5. Paired psychostimulant infusions produced a CPP in the striped visual environment. (A) Five experiences with amphetamine $(5.0 \mu \mathrm{g} / \mathrm{g}$ body weight) or cocaine $(2.5 \mu \mathrm{g} / \mathrm{g}$ body weight) infusions in the striped visual environment fostered relative shifts in spatial use of 46.3 and $24.9 \%$, respectively, such that a place preference for the striped environment was produced $\left(F_{[2,131]}=15.40, P<0.0001\right)$. Independent orthogonal contrasts revealed not only that psychostimulant-conditioned crayfish were distinguishable from controls $(*, P<0.0001)$, but also that amphetamineand cocaine-treated groups were different from each other $(\#, P<0.01$ ). (B) Psychostimulant-induced CPP became progressively stronger as the test session drew on. Conditioning effects became apparent during the second half of the test session $(*, P<0.05)$, with a divergence between the amphetamine and cocaine effects during the final $15 \mathrm{~min}(\#, P<0.01)$.

\subsection{Psychostimulants are rewarding for crayfish exposed to 5 days of a CPP procedure}

The spatial distributions of crayfish conditioned in the striped visual environment for 5 days revealed the existence of an environmental preference resulting from its association with psychostimulant infusions (Fig. 5A; ANOVA main effect, $\left.F_{[2,131]}=15.40, P<0.0001\right)$. Overall, amphetamine infusions produced a $46.3 \%$ increase in use of the striped environment relative to the control condition whereas cocaine induced a $24.9 \%$ relative increase. An $a$ priori (orthogonal) contrast illustrated that amphetamine was a more potent reward than cocaine $\left(F_{[1,131]}=\right.$ $6.10, P<0.01)$. The ANOVA factor demonstrating 
Table 3

A mixed factorial ANOVA with repeated measures was used to analyze the effects of psychostimulant conditioning

\begin{tabular}{|c|c|c|c|c|}
\hline Effect & d.f. & SS & $F$ & $P$-value \\
\hline Drug & 2 & 0.938 & 15.40 & $<0.0001^{*}$ \\
\hline Psychostimulant vs. vehicle & 1 & 0.747 & 24.52 & $<0.0001^{*}$ \\
\hline Amphetamine vs. cocaine & 1 & 0.186 & 6.10 & $<0.01^{*}$ \\
\hline Time & 3 & 0.248 & 2.72 & $<0.05^{*}$ \\
\hline Time bin 1 vs. time bins 2,3 , and 4 & 1 & 0.087 & 2.86 & $<0.05^{*}$ \\
\hline Time bin 2 vs. time bins 3 and 4 & 1 & 0.073 & 2.41 & $=0.062$ \\
\hline Time bin 3 vs. time bin 4 & 1 & 0.091 & 2.98 & $<0.05^{*}$ \\
\hline Drug $\times$ time interaction & 6 & 0.178 & 0.97 & $=0.445$ \\
\hline Time bin 1-psychostimulant vs. vehicle & 1 & 0.100 & 3.29 & $=0.036$ \\
\hline Time bin 2-psychostimulant vs. vehicle & 1 & 0.055 & 1.80 & $=0.091$ \\
\hline Time bin 3-psychostimulant vs. vehicle & 1 & 0.315 & 10.35 & $<0.001^{*}$ \\
\hline Time bin 3-amphetamine vs. cocaine & 1 & 0.053 & 1.74 & $=0.094$ \\
\hline Time bin 4-psychostimulant vs. vehicle & 1 & 0.378 & 12.42 & $<0.001^{*}$ \\
\hline Time bin 4-amphetamine vs. cocaine & 1 & 0.174 & 5.73 & $<0.01^{*}$ \\
\hline
\end{tabular}

A series of orthogonal contrasts were carried out as planned comparisons for each factor. Such tests do not inflate type I error, as the variance components (sums of squares, SS) and degrees of freedom (d.f.) are independent and additive. The SS for the interaction factor did not meet the requirement of additivity and thus the Bonferroni step-down procedure was used to maintain type I error at a constant rate. Asterisks indicate $P$-values that were statistically significant at an experiment-wise $\alpha$ of $P=0.05$.

psychostimulant-conditioning effects in crayfish was particularly robust (statistical power; $1-\beta=0.99$ ) and thereby indicates such effects can be reproduced with a high degree of consistency.

Psychostimulant-induced CPP became even more apparent when duration into the $60 \mathrm{~min}$ test trial was considered (15 min bins; Fig. 5B). Independent of the experimental condition, crayfish exhibited a progressive reduction in locomotion (ANOVA main effect, $F_{[3,127]}=13.64, P<0.0001$ ) where complete acclimation to the aquarium environment occurred between time bin 2 and time bin 3 (orthogonal contrast, $F_{[1,127]}=3.80, P<0.05$ ). Coincident with locomotor acclimation was an increased likelihood of finding crayfish in the drug-conditioned environment (ANOVA main effect $\left.F_{[3,131]}=2.72, P<0.05\right)$. In fact, psychostimulant CPP became most apparent once crayfish had acclimated (Table 3) -reaching $75.7 \pm 5.71 \%$ and $58.2 \pm 5.53 \%$ of the total time spent in the striped environment during the final $15 \mathrm{~min}$ of the test session for amphetamine and cocaine-treated crayfish, respectively. Psychostimulant conditioning effects were not evident when amphetamine or cocaine was paired with the naturally preferred, uniform environment (ANOVA main effect, $F_{[2,132]}=0.70, P=$ 0.499; see Section 4).

\subsection{Amphetamine CPP begins to appear following a single drug exposure}

Another set of conditioning trials was carried out with a specific focus on amphetamine treatment in the striped environment, since this combination of variables was established as the most effective for drug conditioning in the previous experiments. A single drug infusion was given to amphetamine-treated crayfish before the CPP test (i.e., randomly ordered striped/amphetamine and uniform/vehicle pairings were given on the day before testing).

Consistent with all other experiments, vehicle-treated crayfish exhibited a natural preference $(58.4 \pm 2.50 \%$ of the total observation time) for the uniform environment (two-tailed $t$-test $[\mu=50.0 \%] ; t_{[7]}=3.31, P<0.05$ ). Although not statistically significant $\left(F_{[1,17]}=3.43, P<\right.$ 0.10 ), a $28.4 \%$ increase relative to controls once again demonstrated that crayfish had a tendency to spend more time in the striped environment when it was associated with an amphetamine treatment.

\section{Discussion}

The present study built upon several existing lines of research that have explored the neurochemical basis of reward in an invertebrate species (e.g., refs. $[12,33,40,45]$ ) and, furthermore, supported the hypothesis that such studies may tap into fundamental neurobiological alterations that underlie drug addictions $[7,33,58,65]$. It demonstrated that a psychostimulant drug of abuse could be rewarding to an animal that, unlike mammalian species, exhibits a relatively simple neuronal organization. With a nervous system containing fewer than 1000 individually identifiable, monoamine-containing neurons (see ref. [8]), crayfish may thus substantially reduce the complexity associated with studying the primary site of action of psychostimulant drugs.

One of the more conspicuous findings of the present study was the marked dissociation between the effects of amphetamine and cocaine on crayfish behavior. Even at test doses as low as $500 \mathrm{ng} / \mathrm{g}$ body weight (data not shown), a rigid flexed posture always accompanied cocaine injections. Disruption of sensorimotor integration was the first 
consistently demonstrated effect of psychostimulant treatments in mammals, making the present results with cocaine injections not entirely unanticipated. Typically measured through deficits in motor performance or the occurrence of behavioral stereotypies (e.g., refs. [3,53]), such effects have become hallmarks of psychostimulant exposure even when they carry a simultaneous reward value [63]. Conversely, amphetamine treatment induced an exploratory response (which was at times interrupted by ventral side grooming bouts) wherein crayfish appeared to become 'channeled' into using their antennae to investigate the aquarium perimeter. The effects of amphetamine on crayfish behavior appeared more analogous to those reported for mammals [3,14,29,34] and may help furnish hypotheses as to where amphetamine acts in the crayfish central nervous system. For example, systemic injections of DA increase grooming activity in the blue crab, another decapod crustacean species [66].

It might seem unexpected that neither amphetamine nor cocaine increased measures of locomotion, since locomotor activation serves as the most commonly employed measure of behavioral sensitization in mammals. In crayfish, all tested doses of cocaine completely eliminated locomotion whereas amphetamine treatment, if at all, also produced reductions in locomotion (due to the increase in tactile investigation). In a separate set of experiments, continuous delivery of the same dosages of psychostimulants used in the CPP experiments over $30 \mathrm{~min}$, rather than $5 \mathrm{~min}$, also had no effect on locomotion (data not shown). An ethological framework may be useful for understanding this unanticipated result. For instance, in mammals it has been postulated that psychostimulant drugs activate brain systems involved in exploration and novelty [10,29,34,51]. In crayfish, mechanoreception is a significant component of exploring novel environments [6] and, furthermore, dominates their natural behavioral repertoire [17]. The stereotyped tactile investigatory response that accompanied amphetamine treatment in crayfish may thus reflect a species-specific exploratory behavior.

The most significant finding of the present research was that psychostimulants could serve as rewards in crayfish, and it is expected that this initial finding will unfold into a more thorough, systematic characterization of drug-sensitive reward in this group. As such, it will be important to incorporate experimental precedents from drug studies in mammals. For example, it has become clear that reward is not a simple unitary process, but rather a behavioral phenomenon into which an assembly of constituent elements feed (see ref. [9]). In this regard, it has been suggested that the activity of sucrose sensitive neurons in the honeybee brain [40] is compatible with the 'prediction error' hypothesis that was first applied to mammalian DA neurons [54,61]. The present experiments suggested that incentive salience will also be an important hypothetical construct to consider. Crayfish only formed a reward association when amphetamine treatment was paired with the striped environment, but not when it was made contingent upon exposure to the uniform environment. Such specificity may be related to the inherent perceptual salience of the striped visual environment, as the crayfish visual system appears to be particularly adept at extracting vertically oriented contrast information [25]. In fact, this would not be surprising since a similar visual signal can modulate a neural response underlying perceptual salience in Drosophila [59]. Moreover, had crayfish used such contrast features to distinguish between the two environments provided during the CPP experiments, the striped environment may have been perceived as relatively novel (compared to the uniform nature of the other environment in the aquarium or their home container). In this respect, novelty has been strongly implicated in the susceptibility of stimuli to conditioning phenomena [10,16,34,45]. Most importantly, however, the contextual dependence of psychostimulant reward in crayfish can be tested in future experiments.

The suggestion that fruit flies can serve as a model of drug addiction has been fleshed out with a number of molecular, biochemical and behavioral studies (reviewed in ref. [64]). The present results have gone on to demonstrate that studies of reward are well within the scope of invertebrate psychostimulant studies. That the current study revealed the rewarding properties of psychostimulants in a wild-caught population of crayfish (with a correspondingly large effect size and high degree of statistical power) suggests that reward may have a significant impact on the behavior of crayfish in their natural habitat.

Similar to ethanol preference in fruit flies (see ref. [64]), naturalistic interpretations of crayfish drug reward may derive from evolutionary and ecological considerations. For example, it will be important to study the mechanisms by which amphetamine infusions are able to be $\sim$ two-fold more effective than cocaine infusions for crayfish CPP. While the reduced effectiveness of cocaine for crayfish CPP may be accounted for by its primary sites of action [52] or simply by a difference in the dose-response relationship (compared to amphetamine), it may also be due to evolutionary processes [43]. Likewise, it will be essential to explore how both cocaine and amphetamine were able to carry rewarding qualities despite the markedly different effects they had on crayfish behavior.

Can crayfish offer more to studies of psychostimulants in invertebrates, beyond their tractability in behavioral studies? The social consequences of drug abuse are severe [27] and recent findings [42] have corroborated previous work that highlighted the interactions between social processes and psychostimulant exposure $[41,53]$. Crayfish aggression occurs within an intricate social context $[21,30]$, and may thus provide a reductionistic framework for studying the complex relationships between social structure and addictive drugs. Furthermore, although inbreeding and mutagenesis cannot be efficiently carried out in crustacean species, genomic approaches that concurrently measure behavior and gene expression are now available [55,56]. And finally, neurophysiological investigations in decapod crustaceans are not restricted to the neuromuscular junction as they 
have been in flies and worms (see ref. [64]), but rather can be carried out on monoaminergic neurons that can be reliably identified between different subjects (e.g., ref. [24]). Recordings of DA-containing neurons [57] in behaving crayfish may soon be possible [22].

There are distinct experimental advantages to using crayfish in psychostimulant drug studies and thus their use can provide a rich, complementary line of inquiry to research carried out in fruit flies and worms. In particular, the present experiments have shown that crayfish are ideally suited for bringing invertebrate studies of psychostimulants to a level of more complex behavioral phenomena. Psychostimulants appear to carry strong reward value not just from mouse to man, but rather across a much broader evolutionary representation of animal taxa.

\section{Acknowledgements}

We thank members of the Huber laboratory (Jami Barnes, Katie Drerup, Karlo Hock, Angie Pytel, Dr. Vipa Phuntmart, Adam Stocker and Alexis Waggoner) and the van Staaden laboratory (Dr. Vanessa Couldridge, Nate Donelson and Jamie Myers) for their commentary on previous versions of this paper. Furthermore, this project benefited immensely from the constructive criticism and creative input of Dr. Vern Bingman, Jeff Burgdorf, Dr. Casey Cromwell, Dr. Alisdair Daws, Katie Drerup, Scott Hevner, Dr. Jaak Panksepp, Dr. Moira van Staaden and Dr. Dan Wiegmann. Finally, we are grateful to Chris Hess, Deb McClean and Steve Queen for all of their technical assistance.

\section{References}

[1] Abarca C, Albrecht U, Spanagel R. Cocaine sensitization and reward are under the influence of circadian genes and rhythm. Proc Natl Acad Sci 2002;99(13):9026-30.

[2] Andretic R, Chaney S, Hirsh J. Requirement of circadian genes for cocaine sensitization in Drosophila. Science 1999;285:1066-8.

[3] Antoniou K, Kafetzopoulos E, Papadopoulou-Daifoti Z, Marselos M. Damphetamine, cocaine, and caffeine: a comparative study of acute effects on locomotor activity and behavioral patterns in rats. Neurosci Biobehav Rev 1998;23:189-96.

[4] Bainton RJ, Tsai LTY, Singh CM, Moore MS, Neckameyer WS, Heberlein U. Dopamine modulates acute responses to cocaine, nicotine and ethanol in Drosophila. Curr Biol 2000;10:187-94.

[5] Balaban PM, Chase R. Interrelationships of the emotionally positive and negative regions of the brain of the edible snail. Neurosci Behav Physiol 1991;21(2):172-80.

[6] Basil J, Sandeman D. Crayfish (Cherax destructor) use tactile cues to detect and learn topographical changes in their environment. Ethology 2000;106(3):247-59.

[7] Bellen HJ. The fruit fly: a model organism to study the genetics of alcohol abuse and addiction? Cell 1998;93:909-12.

[8] Beltz BS. Distribution and functional anatomy of amine-containing neurons in decapod crustaceans. Microsci Res Tech 1999;44:105-20.

[9] Berridge KC, Robinson TE. What is the role of dopamine in reward: hedonic impact, reward learning, or incentive salience? Brain Res Rev 1998;28:309-68.
[10] Bevins RA, Bardo MT. Conditioned increase in place preference by access to novel objects: antagonism by MK-801. Behav Brain Res 1999;99:53-60.

[11] Borowsky B, Adham N, Jones KA, Raddatz R, Artymyshyn R, Ogozalek KL, et al. Trace amines: identification of a family of mammalian G protein-coupled receptors. Proc Natl Acad Sci 2001;98(16):8966-71.

[12] Brembs B, Lorenzetti FD, Reyes FD, Baxter DA, Byrne JH. Operant reward learning in Aplysia: neuronal correlates and mechanisms. Science 2001;296:1706-9.

[13] Christie AE, Skiebe P, Marder E. Matrix of neuromodulators in neurosecretory structures of the crab Cancer borealis. J Exp Biol 1995;98(12):2431-9.

[14] Cooper SJ, van der Hoek GA. Cocaine: a microstructural analysis of its effects on feeding and associated behaviour in the rat. Brain Res 1993;608:45-51.

[15] Corey JL, Quick MW, Davidson N, Lester HA, Guastella J. A cocaine-sensitive Drosophila serotonin transporter: cloning, expression, and electrophysiological characterization. Proc Natl Acad Sci 1994;91:1188-92.

[16] Crombag HS, Badiani A, Chan J, Dell'Orco J, Dineen SP, Robinson TE. The ability of environmental context to facilitate psychomotor sensitization to amphetamine can be dissociated from its effect on acute drug responsiveness and on conditioned responding. Neuropsychopharmacology 2001;24(6):680-90.

[17] Davis KM, Huber R. Activity patterns, behavioral repertoires, and agonistic interactions of crayfish: a non-manipulative field study. Anim Behav, under review.

[18] Demchyshyn LL, Pristupa ZB, Sugamori KS, Barker EL, Blakely $\mathrm{RD}$, Wolfgang WJ, et al. Cloning, expression, and localization of a chloride-facilitated, cocaine-sensitive serotonin transporter from Drosophila melanogastor. Proc Natl Acad Sci 1994;91:5158-62.

[19] Edwards DH, Issa FI, Herberholz J. The neural basis of dominance hierarchy formation in crayfish. Microsci Res Tech 2003;60:36973.

[20] Evans PD, Kravitz EA, Talam BR. Octopamine release at two points along lobster nerve trunks. J Physiol 1976;262(1):71-89.

[21] Göessman C, Hemelrijk C, Huber R. The formation and maintenance of crayfish hierarchies: behavioral and self-structuring properties. Behav Ecol Sociobiol 2000;48:418-28.

[22] Gruhn M, Rathmayer W. An implantable electrode design for both chronic in vivo nerve recording and axon stimulation in freely behaving crayfish. J Neurosci Methods 2002;118(1):33-40.

[23] Heberlein U. Drugs, flies, and videotape: molecular genetics of drug-induced behaviors in Drosophila. Soc Neurosci Special Lecture $2002 ; 5$.

[24] Heinrich R, Cromarty SI, Horner M, Edwards DH, Kravitz EA. Autoinhibition of serotonin cells: an intrinsic regulatory mechanism sensitive to the pattern of usage of cells. Proc Natl Acad Sci 2002;96:2473-8.

[25] Hernández-Falcón J, Serrato J, Ramón F. Evoked potentials elicited by natural stimuli in the brain of unanesthesized crayfish. Physiol Behav 1999;66(3):397-407.

[26] Hoeger U. Fate of circulating serotonin in the hemolymph of the crayfish, Orconectes limosus. Z Naturforsch 1990;45c:1053-9.

[27] Hser YI, Hoffaman V, Grella CE, Anglin D. A 33-year follow-up of narcotics addicts. Arch Gen Psychiatr 2001;58:503-8.

[28] Huber R, Delago A. Serotonin alters decisions to withdraw in fighting crayfish, Astacus astacus: the motivational concept revisited. J Comp Physiol A 1998;182:573-83.

[29] Ikemoto S, Panksepp J. The role of the nucleus accumbens dopamine in motivated behavior: a unifying interpretation with special reference to reward-seeking. Brain Res Rev 1999;31:6-41.

[30] Issa FA, Adamson DJ, Edwards DH. Dominance hierarchy formation in juvenile crayfish Procambarus clarkii. J Exp Biol 1999;202:3497506. 
[31] Kelly PH, Iversen SD. Selective 6OHDA-induced destruction of mesolimbic dopamine neurons: abolition of psychostimulantinduced locomotor activity in rats. Eur J Pharmacol 1976;40(1):4556.

[32] Kravitz EA. Serotonin and aggression: insights gained from a lobster model system and speculations on the role of amine neurons in a complex behavior. J Comp Physiol A 2000;186:221-38.

[33] Kusayama T, Watanabe S. Reinforcing effects of methamphetamine in planarians. Neuroreport 2000;11(113):2511-3.

[34] Laviola G, Adriani W. Evaluation of unconditioned novelty-seeking and D-amphetamine-conditioned motivation in mice. Pharmacol Biochem Behav 1998;59(4):1011-20.

[35] Li H, Chaney S, Forte M, Hirsh J. Ecotopic G-protein expression in dopamine and serotonin neurons blocks cocaine sensitization in Drosophila melanogaster. Curr Biol 2000;10:211-4.

[36] Livingstone MS, Schaeffer SF, Kravitz EA. Biochemistry and ultrastructure of serotonergic nerve endings in the lobster: serotonin and octopamine are contained in different nerve endings. J Neurobiol 1981;12(1):24-53.

[37] Ma PM, Beltz BS, Kravitz EA. Serotonin-containing neurons in lobsters: their role as gain-setters in postural control mechanisms. J Neurophysiol 1992;68(1):36-56.

[38] McClung C, Hirsh J. The trace amine tyramine is essential for sensitization to cocaine in Drosophila. Curr Biol 1999;9:853-60.

[39] McClung C, Hirsh J. Stereotypical behavioral responses to free-base cocaine and the development of behavioral sensitization in Drosophila. Curr Biol 1998;8(2):109-12.

[40] Menzel R. Searching for the memory trace in a mini-brain, the honeybee. Learn Mem 2001;8:53-62.

[41] Miczek K, Yoshimura H. Disruption of primate social behavior by D-amphetamine and cocaine: differential antagonism by antipsychotics. Psychopharmacology 1982;76:163-71.

[42] Morgan D, Grant KA, Gage HD, Mach RH, Kaplan JR, Prioleau $\mathrm{O}$, et al. Social dominance in monkeys: dopamine D2 receptors and cocaine self-administration. Nature Neurosci 2002;5(2):169-74.

[43] Nathanson JA, Hunnicutt EJ, Kantham L, Scavone C. Cocaine as a naturally occurring insecticide. Proc Natl Acad Sci 1993;90: 9645-8.

[44] Nikaido T, Akiyama M, Moriay T, Shibata S. Sensitized increase of period gene expression in the mouse caudate/putamen caused by repeated injection of methamphetamine. Mol Pharmacol 2001;59(4):894-900.

[45] Nuttley WM, Atkinson-Leadbeater KP, van der Kooy D. Serotonin mediates food-odor associative learning in the nematode Caenorhabditis elegans. Proc Natl Acad Sci 2002;99(19):12449-54.

[46] Palladini G, Ruggeri S, Stocchi F, De Pandis MF, Venturini G, Margotta V. A pharmacological study of cocaine activity in planaria. Comp Biochem Physiol 1996;115C(1):41-5.

[47] Panksepp JB, Huber R. Chronic alterations in serotonin function: dynamic neurochemical properties in agonistic behavior of the crayfish, Orconectes rusticus. J Neurobiol 2002;50(4):276-90.
[48] Pierce RC, Kalivas PW. A circuitry model of the expression of behavioral sensitization to amphetamine-like psychostimulants. Brain Res Rev 1997;25(2):192-216.

[49] Pörzgen P, Park SK, Hirsh J, Sonders MS, Amara SG. The antidepressant-sensitive dopamine transporter in Drosophila melanogastor: a primordial carrier for catecholamines. Mol Pharmacol 2001;59:8395.

[50] Premont RT, Gainetdinov RR, Caron MG. Following the trace of elusive amines. Proc Natl Acad Sci 2001;98(17):9474-5.

[51] Rebec GV, Grabner CP, Johnson M, Pierce RC, Bardo MT. Transient increases in catecholaminergic activity in medial prefrontal cortex and nucleus accumbens shell during novelty. Neuroscience 1997;76(3):707-14.

[52] Ritz MC, Cone EJ, Kuhar MJ. Cocaine inhibition of ligand binding at dopamine, norepinephrine, and serotonin transporters: a structure-activity study. Life Sci 1990;46:635-45.

[53] Sahakian BJ, Robbins TW, Morgan MJ, Iversen SD. The effects of psychomotor stimulants on stereotypy and locomotor activity in socially-deprived and control rats. Brain Res 1975;84(2):195-205.

[54] Schultz W. Dopamine neurons and their role in reward mechanisms. Curr Opin Neurobiol 1997;7(2):191-7.

[55] Spitzer N, Baro DJ, Edwards DH. Social regulation of serotonin receptors in the CNS of crayfish. Soc Neurosci Absract 2002;59.4.

[56] Stocker AM, Huber R. Identification of changes in gene expression resulting from chronic serotonin treatment in the crayfish, Orconectes rusticus. Soc Neurosci Abstract 2002;879.4.

[57] Tierney AJ, Kim T, Abrams R. Dopamine in crayfish and other crustaceans: distribution in the central nervous system and physiological functions. Microsc Res Tech 2003;60:325-35.

[58] Torres G, Horowitz JM. Activating properties of cocaine and cocaethylene in a behavioral preparation of Drosophila melanogastor. Synapse 1998;29:148-61.

[59] van Swinderen B, Greenspan RJ. Salience modulates $20-30 \mathrm{~Hz}$ brain activity in Drospohila. Nature Neurosci 2003;6(6):579-86.

[60] Vezina P, Stewart J. The effect of dopamine receptor blockade on the development of sensitization to the locomotor activating effects of amphetamine and morphine. Brain Res 1989;499:108-20.

[61] Waelti P, Dickinson A, Schultz W. Dopamine responses comply with basic assumptions of formal learning theory. Nature 2001;412:43-8.

[62] Wise RA, Bozarth MA. A psychomotor theory of addiction. Psychol Rev 1987;94:469-92.

[63] Wyvell CL, Berridge KC. Incentive sensitization by previous amphetamine exposure: increased cue-triggered "wanting" for sucrose reward. J Neurosci 2001;21(19):7831-40.

[64] Wolf FW, Heberlein U. Invertebrate models of drug abuse. J Neurobiol 2003;54(1):161-78.

[65] Wolf ME. Cocaine addiction: clues from Drosophila on drugs. Curr Biol 1999;9:R770-2.

[66] Wood DE, Gleeson RA, Derby CD. Modulation of behavior by biogenic amines and peptides in the blue crab, Callinectes sapidus. J Comp Physiol A 1995;177:321-33. 